\title{
Emergency Contraception Awareness in an At-Risk Population
}

Ms Denise L $\underline{\mathrm{HOPE}}^{1 *}$, Associate Professor H Laetitia $\underline{\mathrm{HATTINGH}}{ }^{2}$, Dr Michelle A $\underline{\mathrm{KING}}^{3}$

${ }^{1}$ BPharm, MMedRes, GradCertHigherEd, SFHEA

Menzies Health Institute Queensland, Quality Use of Medicines Network, School of

Pharmacy and Pharmacology, Clinical Sciences 2, Gold Coast Campus, Griffith University, Queensland, Australia

${ }^{2}$ MPharm, BPharm, GCAppLaw, Cert4 TAA, AACP, PhD

Quality Use of Medicines Network, School of Pharmacy and Pharmacology, Clinical

Sciences 2, Gold Coast Campus, Griffith University, Queensland, Australia

${ }^{3}$ BPharm, $\mathrm{PhD}$ (Med)

Menzies Health Institute Queensland, Quality Use of Medicines Network, School of Pharmacy and Pharmacology, Clinical Sciences 2, Gold Coast Campus, Griffith University, Queensland, Australia

Author for correspondence:

Denise L. Hope

School of Pharmacy and Pharmacology, Clinical Sciences 2, G16_3.26

Gold Coast Campus, Griffith University Qld 4222 Australia

Telephone: 61-7-5552 7339

Fax: $\quad$ 61-7-5552 8804

Email: $\quad$ d.hope@griffith.edu.au

No conflicts of interest declared.

\section{Acknowledgements}

This research was funded by a research grant from the Quality Use of Medicines (QUM)

Network, in partnership with the Griffith University School of Pharmacy and Pharmacology.

The authors would like to acknowledge the Schoolies that participated in the research, the

Safer Schoolies Initiative, and the Schoolies team from Gold Coast Health. 


\begin{abstract}
Background

Consumer awareness of emergency contraception is generally poor. School leavers

(Schoolies) engage in risky behaviours, including casual sex, alcohol and drug consumption.

\section{Aim}

To explore the awareness of an at-risk population of Schoolies regarding the use and availability of emergency contraception.
\end{abstract}

\title{
Method
}

An electronic survey was self-administered by participants using Wi-Fi-connected iPads at the Schoolies Wristband Distribution Centre, Surfers Paradise, on the first day of Queensland Schoolies Week, November 2017. Outcomes measured were awareness of availability of emergency contraception from a pharmacy; maximum time for effective use following unprotected intercourse; and whether emergency contraception is harmful to the health of the user.

\section{Results}

Schoolies completed 498 valid surveys. The majority were aged 17 years $(83.5 \%)$ and $50.8 \%$ were aware that emergency contraception is available from community pharmacies with prescription and $36.7 \%$ that it is available without prescription; $18.5 \%$ were aware of the 72 or 120 hour effectiveness window, and 38.0\% agreed it is not harmful. All questions were associated with considerable uncertainty. Females were 1.8 to 3.2 times more likely than males to provide an appropriate response to any emergency contraception statement.

\section{Conclusion}

Schoolies' awareness of emergency contraception availability, effectiveness window and safety was low. At-risk Schoolies may not access emergency contraception when indicated due to fear of harm, uncertainty about its effectiveness window or lacking knowledge about timely non-prescription access from community pharmacies. Targeted education may improve current knowledge gaps. The misnomer 'morning after pill' should be abandoned for the clinically appropriate term 'emergency contraception'.

\section{Keywords}

Contraception, post-coital; adolescents; community pharmacies; Public Health; Nonprescription Drugs. 


\section{Introduction}

Consumer awareness of emergency contraception (EC) in Australia is traditionally poor. ${ }^{1-5}$ EC is any method used following unprotected sexual intercourse to prevent unintended pregnancy, due to lack of contraception, contraceptive failure or sexual assault. ${ }^{1}$ Oral EC is considered safe, effective and potentially cost-effective to consumers with positive public health outcomes. ${ }^{6}$ Oral levonorgestrel has been available as a non-prescription emergency contraceptive in Australia since $2004^{7}$ and is approved for use as a $1.5 \mathrm{mg}$ single dose for up to 72 hours (three days) following unprotected intercourse. ${ }^{8}$ In February 2017, oral ulipristal was also made available without prescription ${ }^{9}$ and is approved as a $30 \mathrm{mg}$ single dose for up to 120 hours (five days) following unprotected intercourse. ${ }^{8}$

Despite the non-prescription availability of levonorgestrel from community pharmacies since 2004, a 2011 national Australian survey identified that the majority of women were aware EC existed but less than half knew that it was available from pharmacies without prescription. ${ }^{4} \mathrm{~A}$ 2009 study reported that Australian university students' knowledge about the timing, accessibility, action and side effects of EC was poor. ${ }^{1}$ Of interest is whether awareness has changed with the current availability of two forms of EC, levonorgestrel and ulipristal, and with effective use extended to three and five days respectively following unprotected intercourse.

Tens of thousands of Australian school leavers, aged 16 to 18 years, celebrate high school graduation by attending 'Schoolies Week' festivities on the Gold Coast, Queensland, during November and December each year. Alcohol, other drug use, and sexual activity at this and other Schoolies destinations is common ${ }^{10-15}$ and the risk of unintended pregnancy may be quite high. ${ }^{10}$ Recent studies of Schoolies' behaviours are lacking, however, the majority of Gold Coast Schoolies in a 1995 study by Smith and Rosenthal reported getting drunk most or every day or night, and about a third of females and almost half of males reported being 'stoned' at some point during Schoolies, while 39\% reported having sex. ${ }^{10}$ Of those that engaged in unprotected intercourse with casual partners $20.1 \%$ were uncertain whether any form of contraception was used. ${ }^{10}$ Similar results were obtained by Maticka-Tyndale et al three years later with $34.5 \%$ of males and $23.6 \%$ of females reporting that they had sex during Schoolies Week. ${ }^{12}$ Of those having sex over $60 \%$ of the males and almost $40 \%$ of the females engaged in sexual intercourse with a casual partner. ${ }^{12}$ 
Research into Schoolies behaviour in Victoria and Western Australia also identified risks. The use of alcohol and drugs by Rottnest Island Schoolies, Western Australia, increased the risk of unprotected sex. ${ }^{15}$ Research into risky behaviours of Victorian Schoolies identified that $21.1 \%$ experienced some form of alcohol-related harm, including unprotected sex. ${ }^{14}$ Illicit drug use was associated with six times the likelihood of engaging in unprotected casual sex $(\mathrm{OR}=6.3,95 \% \mathrm{CI} 2.1-18.8) .{ }^{14}$ Alcohol and drug use were reported as reasons for unwanted sex in a national survey of secondary students. ${ }^{16}$ The same survey found that $5 \%$ of sexually active students 'had sex that resulted in a pregnancy'. ${ }^{16}$

Given the risk of unprotected sex and potential unintended pregnancy, awareness of EC in the Schoolies population is important in terms of public health risk assessment and management. This is particularly relevant considering the expansion of non-prescription EC options in the Australian context. The aim of the study was to investigate Queensland Schoolies' awareness of EC availability, effectiveness and safety.

\section{Method}

This study involved an online self-administered survey and was approved by the Griffith University Research Ethics Committee (2017/566) and the Safer Schoolies Initiative.

\section{Procedure}

Data collection was conducted by the authors and four research assistants on 18 November 2017, the first day of the Queensland Schoolies Week at the Schoolies Wristband Distribution Centre, Surfers Paradise. The Wristband Distribution Centre is a government-run outdoor location that distributes requisite wristbands to Schoolies attendees once they are validated as genuine school leavers. All Schoolies require a wristband to attend festival activities and 95\% of attendees $(12,923$ of a total 13,549$)$ collected them from the Distribution Centre on the first day of Schoolies week. Queensland Schoolies were approached in person as they moved through and around the outdoor location area and invited to participate in the study. Attendees within the vicinity of the researchers were approached. No further inclusion/exclusion criteria were applied. Interested participants were subsequently handed an iPad tablet device that was remotely Wi-Fi-connected to the internet. The device showed a study information sheet with a link to a brief, anonymous, self-administered electronic survey hosted in Lime Survey ${ }^{\mathrm{TM}}$. Survey design was purposefully brief to assist in the timely completion by Schoolies attendees as they moved around the Wristband Distribution Centre. 
Participants were offered a \$5 (AUD) food voucher as a token of appreciation. Data collection was ceased once 500 incentives were distributed.

\section{Measures}

The survey consisted of four demographic statements i.e. gender, age, cultural group and whether they were a Schoolie or not, and three EC statements. Participants were asked to select yes, no or uncertain in response to the EC statements. Statements pertaining to EC were on the availability of EC tablets from a pharmacy, both with and without a prescription (availability); maximum time for effective use following unprotected intercourse (effectiveness window); and whether EC is harmful to the health of the user (safety). The statements were developed considering the literature, the Australian context and the research team expertise. The question on harm derived from a 2007 Australian study that investigated men's beliefs on contraception, in which $32 \%$ of respondents rated emergency contraception worst of all contraceptive methods in relation to perceived harmfulness. ${ }^{17}$ The survey was initially piloted with two academic colleagues and three adolescents of the target age group who were not attending Schoolies. No changes were made.

\section{Analysis}

Survey data were extracted from the Lime Survey ${ }^{\mathrm{TM}}$ tool and imported into SPSSv22. Only data from those self-identifying as Schoolies were included in the analysis. Responses that included data that were questionable, e.g. age $>90$, were excluded.

Descriptive analyses were performed for all variables. Responses were compared based on age, gender (male or female) and cultural group (Australian, New Zealander or Pacific Islander or not) using the Chi-squared test with $\mathrm{p}<0.05$ considered to be statistically significant. Odds ratios and $95 \%$ confidence intervals were calculated for the number of appropriate responses from males and females. Due to the availability of two EC options both 72 and 120 hours were considered to be appropriate responses to the maximum time after unprotected sex that EC can be taken for it to be effective (effectiveness window).

\section{Results}

Five hundred and seventeen online surveys were completed, which represented $12.5 \%$ of the 4,151 Schoolies that checked in at the Wristband Distribution Centre during the period of data collection (prior to $2 \mathrm{pm}$ on 18 November). As attendees were spread over a large 
geographical area and at times were gathered in large groups, it is difficult to determine the exact response rate, however, very few Schoolies approached in person declined to participate. Of the surveys completed 498 were included in the analysis. The majority of respondents identified as Australian, New Zealander, or Pacific Islander and were 17 years of age (Table 1).

Overall, the percentage of appropriate responses for each statement was (Table 2): 50.8\% available from community pharmacy with a prescription, $36.7 \%$ available from community pharmacy without a prescription, $18.5 \%$ for the combined options of 72 and 120 hour effectiveness windows, and $38.0 \%$ not harmful. Females were significantly $\left(\chi^{2} p \leq 0.001\right)$ more likely than males to provide an appropriate response to any EC statement: OR $(95 \% \mathrm{CI})$ 1.80 (1.26-2.58) available from community pharmacy with a prescription, 1.85 (1.27-2.68) available from community pharmacy without a prescription, 2.34 (1.61-3.41) 72 or 120 hour effectiveness window, and $3.20(1.92-5.33)$ not harmful. Age and whether or not a person identified as Australian, New Zealander or Pacific Islander were not associated with the proportion of appropriate responses for any statement $\left(\chi^{2} p>0.05\right)$.

\section{Discussion}

Schoolies' awareness of EC availability, effectiveness and safety was low. Approximately half the respondents were aware that EC could be obtained from a pharmacy with a doctor's prescription, while just over a third knew that it was available from a pharmacy without a prescription. There was considerable uncertainty associated with every statement.

Timely access to EC is closely related to its efficacy. Community pharmacies facilitate prompt non-prescription EC access, providing an opportunity to meet an important therapeutic need. ${ }^{8}$ Lack of awareness that EC can be obtained from a community pharmacy is a barrier to timely provision of EC, increasing the risk of unintended pregnancy. Pharmacists are able to assess a patient's situation and potential risk, and offer patient-centred management strategies, whether it involves medicines provision or referral to another health professional, such as a medical doctor or sexual health clinic.

Approximately one in five Schoolies surveyed were uncertain about the effectiveness window of EC. Half of the respondents indicated that the window of effectiveness was either 12 or 24 hours, which is concerning, although not as concerning as a study that showed $75 \%$ 
of Australian university students thought EC could only be used 'the morning after". ${ }^{1}$ This is particularly relevant, given the recent reclassification of ulipristal to a non-prescription medicine, which has essentially extended the effectiveness window for safe and effective use from three to five days post-intercourse. These findings raise the question as to whether the term 'morning after pill' is responsible for confusing those at risk from unintended pregnancy.

More than a quarter of Schoolies believed EC was harmful to the user, with another third of respondents unsure whether EC was harmful. This was slightly less than a 2017 study regarding attitudes towards contraception of men using an online dating service, in which $32 \%$ of respondents thought that EC was harmful to the user and $37 \%$ were unsure. ${ }^{17} \mathrm{~A}$ misbelief that EC is harmful may deter potential users from seeking the medicine. They may believe that the potential risk of an unintended pregnancy outweighs the risk of the medicine. The difference in knowledge between male and female Schoolies was significant for all EC statements, with females up to 3.2 times more likely to choose the appropriate option. While Calabretto (2009) found that females were significantly more likely than males to correctly answer a question relating to the effectiveness window of 120 hours, she identified no significant differences for availability either with or without a doctor's prescription from pharmacies. It should be noted that, at the time of the Calabretto (2009) study, levonorgestrel was only approved in Australia for use up to 72 hours following unprotected intercourse, even though it was thought to have some efficacy up to 120 hours. Calabretto suggested that increased EC awareness in females may be because an unplanned pregnancy has a greater impact on a woman than a man. ${ }^{1}$

Secondary schools have an important role to play in sexuality education. A 2010 report stated that students identified school health programs as one of the most used sources of information regarding sexual health; second only to the internet. ${ }^{18}$ It identified that sexuality education was not taught in all Australian secondary schools or that the persons providing the education may have had limited formal training or experience of teaching in this area. ${ }^{18}$ The dearth of evidence-based information about EC from such an important source may contribute to Schoolies' lack of EC knowledge.

The Queensland Schoolies 2017 website provided advice to attendees about unprotected sex, which recommended visiting 'your local doctor, family planning clinic or sexual health clinic for a sexual health check'. ${ }^{19}$ However, the advice did not include information relating to 
accessing EC or list community pharmacy as a resource, overlooking the rapid access to EC through this source. Pharmacies are also an accessible source of free advice, provision of support relating to sexual health and referral as necessary. Pharmacists' provision of health promotion services, including supply of hormonal contraceptives, is consistent with the International Pharmaceutical Federation (FIP) definition of comprehensive pharmacy services that contribute to harm reduction. ${ }^{20}$ Additionally, the provision of EC provides an ideal opportunity for pharmacists to address chlamydia screening ${ }^{21-23}$ or other risky behaviours, for example, alcohol screening with brief advice. ${ }^{24}$ The availability of EC through community pharmacies therefore offers a range of public health benefits.

In June 2017 the Australian Therapeutic Goods Administration (TGA) approved a request to allow direct-to-consumer advertising of ulipristal. This change took effect on 1 February $2018 .^{25}$ It is hypothesised that this direct-to-consumer advertising will improve general community knowledge of various aspects of EC. The ethical clearance of this project allows for repetition of the data collection at future Schoolies to test this hypothesis.

\section{Limitations}

Data collection was conducted during a short time window and only included Queensland Schoolies at the Gold Coast and, as such, may not reflect the knowledge of those not attending these celebrations or Schoolies from other states. The risk profiles of Schoolies attendees may also vary from school leavers who do not attend similar celebrations.

\section{Conclusion}

The lack of knowledge relating to EC availability, its window of effectiveness and safety in an at-risk population is concerning. Schoolies may not access EC when needed due to fear of harm, thinking that it would no longer be effective or not knowing about accessing it from a community pharmacy in a timely manner. There may be ways to improve this situation, for example, abandoning the misnomer of 'morning after pill' and replacing it with the clinically appropriate term 'emergency contraception' especially in the media. Targeted education may also help to address current knowledge gaps. 


\section{References}

1. Calabretto H. Emergency contraception - knowledge and attitudes in a group of Australian university students. Australian and New Zealand Journal of Public Health. 2009;33(3):234239.

2. Mohoric-Stare D, De Costa C. Knowledge of emergency contraception amongst tertiary students in far North Queensland. Australian and New Zealand Journal of Obstetrics and Gynaecology. 2009;49(3):307-311.

3. Downing SG, Payze C, Doyle-Adams S, Gorton C. Emergency contraception over-thecounter: Practices and attitudes of pharmacists and pharmacy assistants in far North Queensland. Australian and New Zealand Journal of Obstetrics and Gynaecology. 2011;51(6):527-531.

4. Hobbs MK, Taft AJ, Amir LH, et al. Pharmacy access to the emergency contraceptive pill: a national survey of a random sample of Australian women. Contraception. 2011;83(2):151158.

5. Hussainy SY, Stewart K, Chapman CB, et al. Provision of the emergency contraceptive pill without prescription: attitudes and practices of pharmacists in Australia. Contraception. 2011;83(2):159-166.

6. Bayer LL, Edelman AB, Caughey AB, Rodriguez MI. The price of emergency contraception in the United States: what is the cost-effectiveness of ulipristal acetate versus single-dose levonorgestrel? Contraception. 2013;87(3):385-390.

7. National Drugs and Poisons Schedule Committee. Record of Reasons 39th Meeting 14-16 October, 2003, 12.1 Levonorgestrel Canberra: Department of Health and Ageing; 2003:62-67, 141-147.

8. Pharmaceutical Society of Australia. Guidance for the provision of a Pharmacist Only medicine - Emergency contraception 2017; https://my.psa.org.au/s/sfdcpage/\%2Fapex\%2FAsKnowledgeArticle\%3FartType\%3DStandar d_kav\%26artId\%3Dka17F0000000yJ1QAI. Accessed 9 October 2018.

9. Therapeutic Goods Administration. Scheduling delegate's final decisions, July 2016, 4.1 Ulipristal. 2016; https://www.tga.gov.au/book-page/41-ulipristal. Accessed 9 October 2018.

10. Smith A, Rosenthal D. Sex, alcohol and drugs? Young people's experience of Schoolies Week. Australian and New Zealand Journal of Public Health. 1997;21(2):175-180.

11. Zinkiewicz L, Davey J, Curd D. Sin beyond Surfers? Young people's risky behaviour during Schoolies Week in three Queensland regions. Drug and Alcohol Review. 1999;18(3):279-285.

12. Maticka-Tyndale E, Herold ES, Oppermann M. Casual sex among Australian schoolies. Journal of sex research. 2003;40(2):158-169.

13. Salom C, Watts M, Kinner S, Young D. Schoolies week in perspective: Studies of alcohol, drug and risk-taking behaviour. Of Substance: The National Magazine on Alcohol, Tobacco and Other Drugs. 2005;3(1):26.

14. Lubman DI, Droste N, Pennay A, Hyder S, Miller P. High rates of alcohol consumption and related harm at schoolies week: a portal study. Australian and New Zealand journal of public health. 2014;38(6):536-541.

15. Lam T, Liang W, Chikritzhs T, Allsop S. Alcohol and other drug use at school leavers' celebrations. Journal of Public Health. 2013;36(3):408-416.

16. Mitchell A, Patrick K, Heywood W, Blackman P, Pitts M. 5th National Survey of Australian Secondary Students and Sexual Health 2013 (ARCSHS Monograph Series No. 97). 2014; http://apo.org.au/node/39558. Accessed 9 October 2018.

17. Stewart M, Ritter T, Bateson D, McGeechan K, Weisberg E. Contraception-what about the men? Experience, knowledge and attitudes: a survey of 2438 heterosexual men using an online dating service. Sexual Health. 2017.

18. Smith A, Schlichthorst M, Mitchell A, et al. Sexuality Education in Australian Secondary Schools 2010. 2011; http://apo.org.au/node/53187. Accessed 9 October 2018.

19. Queensland Government. Schoolies: Staying Safe - Sexual Health. 2018; https://www.schoolies.qld.gov.au/staying-safe/sexual-health. Accessed 9 October 2018. 
20. International Pharmaceutical Federation. Reducing harm associated with drugs of abuse: The role of pharmacists. 2017; https://www.fip.org/files/fip/publications/Reducing-harmassociated-drugs-abuse.compressed.pdf. Accessed 9 October 2018.

21. Brabin L, Thomas G, Hopkins M, O'Brien K, Roberts SA. Delivery of chlamydia screening to young women requesting emergency hormonal contraception at pharmacies in Manchester, UK: a prospective study. BMC Women's Health. 2009;9(1):7.

22. Thomas G, Humphris G, Ozakinci G, et al. A qualitative study of pharmacists' views on offering chlamydia screening to women requesting emergency hormonal contraception. BJOG: An International Journal of Obstetrics \& Gynaecology. 2010;117(1):109-113.

23. Gudka S, Bourdin A, Watkins K, Eshghabadi A, Everett A, Clifford RM. Self-reported risk factors for chlamydia: a survey of pharmacy-based emergency contraception consumers. International Journal of Pharmacy Practice. 2014;22(1):13-19.

24. Brown S, Henderson E, Sullivan C. The feasibility and acceptability of the provision of alcohol screening and brief advice in pharmacies for women accessing emergency contraception: an evaluation study. BMC Public Health. 2014;14(1):1139.

25. Therapeutic Goods Administration. Scheduling delegate's final decisions, June 2017, 1.3 Ulipristal. 2017; https://www.tga.gov.au/book-page/13-ulipristal-0. Accessed 9 October 2018. 
Table 1: Participant demographics

\begin{tabular}{lrl}
\hline Demographic Characteristic & $\mathrm{n}$ & $(\%)$ \\
\hline Gender & & \\
Male & 232 & $(46.6)$ \\
Female & 265 & $(53.2)$ \\
Other & 1 & $(0.2)$ \\
Age & & \\
16 & 23 & $(4.6)$ \\
17 & 416 & $(83.5)$ \\
18 & 59 & $(11.8)$ \\
Cultural Group* & 15 & $(3.0)$ \\
African & 7 & $(1.4)$ \\
Asian, east or southeast, e.g. Vietnamese & 7 & $(1.4)$ \\
Asian, sub-continent, e.g. Indian & 440 & $(88.4)$ \\
Australian, New Zealander or Pacific Islander & 32 & $(6.4)$ \\
European and United Kingdom & 5 & $(1.0)$ \\
Middle Eastern & 2 & $(0.4)$ \\
North American & 4 & $(0.8)$ \\
South American & 2 & $(0.4)$ \\
Other & $>100 \%$
\end{tabular}


Table 2: EC responses by gender, age and cultural group

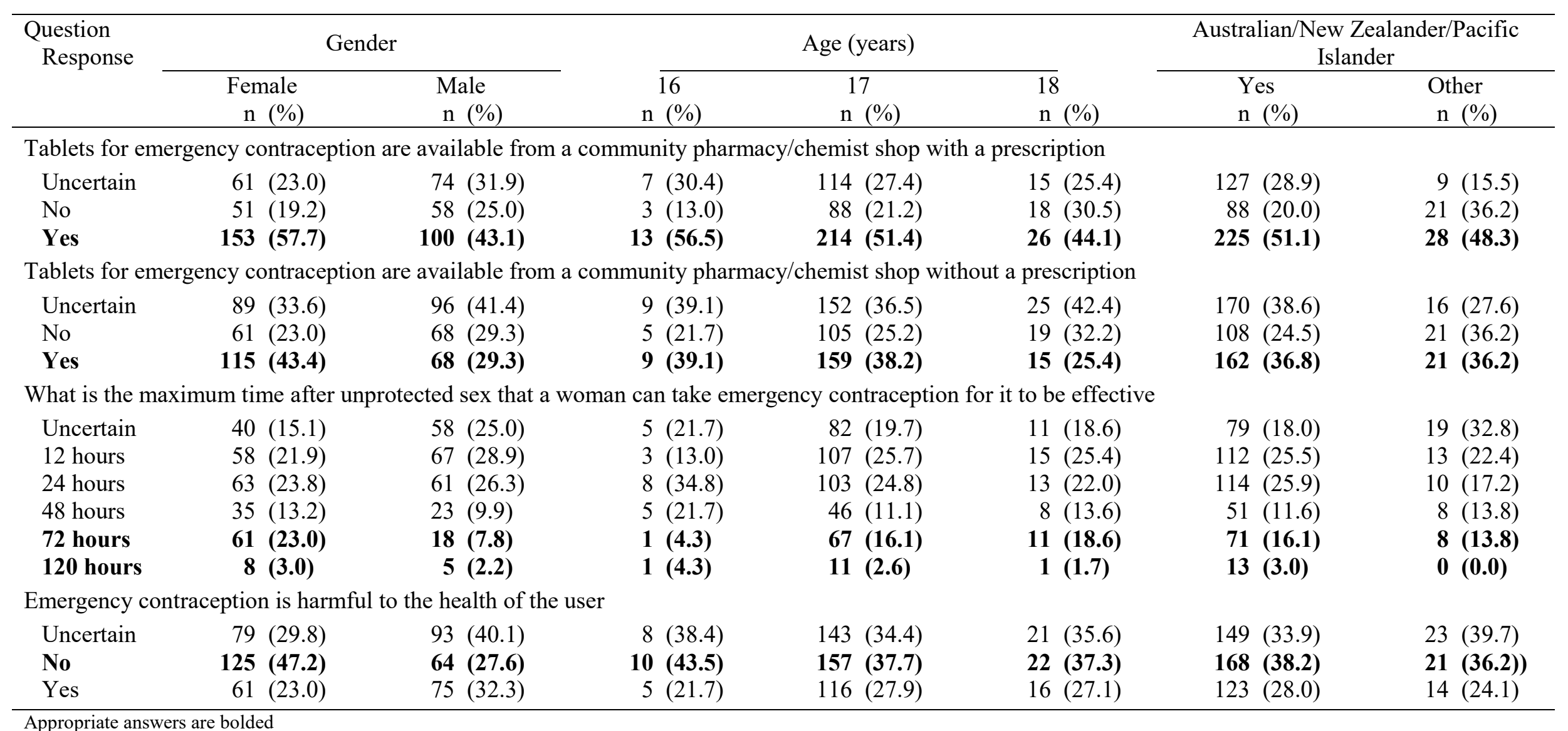

